\title{
Outcomes of antifungal prophylaxis in high-risk liver transplant recipients
}

\author{
S. Hadley, C. Huckabee, P.G. Pappas, J. Daly, J. Rabkin, C.A. Kauffman, \\ R.M. Merion, A.W. Karchmer. Outcomes of antifungal prophylaxis in \\ high-risk liver transplant recipients. \\ Transpl Infect Dis 2009: 11: 40-48. All rights reserved
}

\begin{abstract}
Antifungal prophylaxis for liver transplant recipients (LTRs) is common among patients considered at high risk of infection, but optimal prophylaxis duration and drug has not been defined. This study aimed to assess the effects of 14 days of antifungal therapy prophylaxis in reducing proven invasive fungal infections (IFI) in high-risk subjects. Eligible subjects who met 2 or more risk criteria were randomized 1:1 to the treatment arms (liposomal amphotericin B or fluconazole) and were followed for 100 days post transplantation for evidence of IFI. The study was designed to enroll 300 subjects, but was closed early for insufficient enrollment. A total of 71 subjects were enrolled and randomized. Two-thirds of subjects completed 14 days of study therapy. Ten subjects developed proven or probable IFI with Candida species (9 subjects) and Cryptococcus neoformans (1 subject); rates were similar in the 2 treatment arms. Eleven subjects died, but no death was attributed to study drug or IFI. In summary, high-risk LTRs tolerated antifungal prophylaxis well, and rates of IFI were lower than previously reported in untreated high-risk LTRs.
\end{abstract}

\author{
S. Hadley ${ }^{1}$, C. Huckabee ${ }^{2}$, P.G. Pappas ${ }^{3}$, \\ J. Daly ${ }^{4}$, J. Rabkin ${ }^{5, *}$, C.A. Kauffman ${ }^{6}$, \\ R.M. Merion? ${ }^{7}$ A.W. Karchmer \\ ${ }^{1}$ Division of Geographic Medicine and Infectious Diseases, \\ Tufts Medical Center, Boston, Massachusetts, USA, \\ ${ }^{2}$ Bacteriology and Mycology Biostatistics and Operations \\ Unit, Rho Federal Systems Division Inc., Chapel Hill, North \\ Carolina, USA, ${ }^{3}$ Division of Infectious Diseases, University of \\ Alabama at Birmingham, Birmingham, Alabama, USA, \\ ${ }^{4}$ Department of Medicine, University of Massachusetts \\ Medical School, Worcester, Massachusetts, USA, \\ ${ }^{5}$ Department of Surgery, Section of Liver Transplantation at \\ Oregon Health and Sciences University in Portland, Oregon \\ Health and Sciences University, Portland, Oregon, \\ ${ }^{6}$ Department of Internal Medicine, University of Michigan \\ Medical Center and Veterans Affairs Ann Arbor Healthcare \\ System, Ann Arbor, Michigan, USA, ${ }^{7}$ Department of Surgery, \\ University of Michigan Medical Center, Ann Arbor, Michigan, \\ USA, ${ }^{8}$ Division of Infectious Diseases, Beth Israel Deaconess \\ Medical Center, Boston, Massachusetts, USA
}

Key words: antifungal; fungal infections; liver transplantation; prophylaxis; liposomal amphotericin B; fluconazole

\author{
Correspondence to: \\ Tel: + 16075473390 \\ Fax: + 16075474973 \\ E-mail: susan.hadley@bassett.org \\ publication 26 September 2008 \\ DOI: 10.1111/j.1399-3062.2008.00361.x \\ Transpl Infect Dis 2009: 11: $40-48$
}

Susan Hadley, MD, Bassett Healthcare, Division of Infectious Diseases, One Atwell Road, Cooperstown, NY 13326 USA

*Present address: Department of Transplantation at California Pacific Medical Center, San Francisco, CA, USA.

Received 9 April 2008, revised 1 August 2008, accepted for
Invasive fungal infections (IFI) are a major cause of morbidity and mortality among patients undergoing orthotopic liver transplantation (OLT). Although surgical techniques and immunosuppressive regimens have

These data were presented at the Infectious Diseases Society of America (IDSA) 41st Annual Meeting in San Diego, California, USA, 2003. evolved to reduce mechanical complications and rejection episodes in liver transplant recipients (LTRs), the incidence of IFI remains between $6 \%$ and $47 \%(1-5)$. Mortality associated with these infections may be as high as $32 \%$ $(6,7)$. Candida species account for the majority of infections, followed by Aspergillus species, other molds, and Cryptococcus neoformans (8-11).

Despite the serious consequences of IFI in LTRs, a definitive strategy for prevention of this complication has not 
yet emerged (12-14). The patient undergoing OLT today is generally sicker than a decade ago, owing to advances in medical therapy of end-stage liver disease and worsening organ shortage. Increased patient complexity necessitates assessment of risk for serious fungal infections after transplantation and subsequent preventative intervention. Well-defined preoperative and intraoperative risk factors associated with IFI have been documented in numerous studies and include preoperative renal failure, low serum albumin, retransplantation, substantial infusions of intraoperative cellular blood products, a choledochojejunostomy anastomosis, Candida colonization, early graft failure, and re-exploration after OLT $(3,8,15-18)$. Over a 13 -year-period in one center, perioperative risk factors were identified in 2 retrospective LTR cohorts and subsequently prospectively validated $(8,16,19)$. LTRs with 2 or more perioperative risk factors were at substantially higher risk for IFI than those with 0 or 1 risk factor ( $34 \%$ vs. $3 \%$, respectively) (19). These data suggest that IFI are concentrated in a specific subpopulation of LTRs, and those risks may be assessed and addressed in the perioperative period.

The aim of this study was to evaluate the safety and efficacy of antifungal therapy (liposomal amphotericin B [L-amB] and fluconazole) in patients undergoing OLT who are at high risk for IFI. A companion study assessing the natural history of IFI in low-risk LTRs has been reported (20). Our study was terminated early due to slow enrollment and unlikely completion of the trial in a timely manner. In this report, we describe the aggregate data and implications for future studies.

\section{Methods}

\section{Study design and population}

This prospective, double-blind, randomized trial was designed to evaluate the safety and efficacy of intravenous $\mathrm{L}$-amB $2 \mathrm{mg} / \mathrm{kg}$ vs. fluconazole $400 \mathrm{mg}$ daily for 14 days after randomization in 300 high-risk LTRs. The study was approved by the institutional review board (IRB) of each site.

All patients who underwent OLT at study sites were screened for eligibility. An IRB-approved informed written consent was obtained from patients at each site before performing tests exclusively required for determination of eligibility for this trial. Subjects $\geq 18$ years of age satisfied the screening criteria if the initial immunosuppressive regimen included tacrolimus and they were scheduled to receive nystatin $500,000 \mathrm{U} 4$ times daily as oral nonabsorbable antifungal prophylaxis for the first 60 days post transplant.
Subjects satisfying the screening criteria were considered for enrollment if they met 2 or more of the following high-risk perioperative criteria documented within 5 days of OLT: 1) a choledochojejunostomy anastomosis; 2) retransplantation; 3 ) intraoperative administration of $\geq 40 \mathrm{U}$ of cellular blood products (platelets or packed red blood cells excluding cryoprecipitate and plasma); 4) return to the operating room within 5 days for laparotomy for intra-abdominal bleeding or repair of bile or other viscous leak, vascular accident other than bleeding, or acute graft failure; 5) preoperative serum creatinine $\geq 2.0 \mathrm{mg} /$ $\mathrm{dL}$ or need for any form of dialysis within $48 \mathrm{~h}$ before OLT; and 6) Candida species isolated from cultures obtained within $48 \mathrm{~h}$ before or after OLT from one or more of the following sites: sputum, urine, wound, Jackson-Pratt drainage, intra-operative recipient bile/biliary tree, or T-tube drainage.

Eligible subjects were enrolled, stratified by cytomegalovirus (CMV) serostatus, and randomized within 5 days of OLT to receive either intravenous L-amB $2 \mathrm{mg} / \mathrm{kg}$ or fluconazole $400 \mathrm{mg}$ daily for 14 days. Subjects were followed at specified intervals for clinical and microbiological events for 100 days post OLT. Surveillance fungal cultures were collected from available sites (sputum, urine, wound, rectum, Jackson-Pratt drains, and T-tube drainage) on study days $3,7,10,14,28,42,70$, and 100 post OLT.

\section{Definitions}

The primary endpoint was defined in the protocol to be the incidence of proven IFI within 100 days after OLT.The combined incidence of proven and probable IFI within 100 days after OLT and mortality at 100 days after OLT were both planned secondary endpoints.

Proven and probable IFI were defined based on MSG/ EORTC criteria and assessed by a masked data review committee utilizing the same criteria (21).

Death was considered related to IFI based on post-mortem evidence or recovery of a fungus from blood or another sterile site within $48 \mathrm{~h}$ of death.

\section{Power and sample size}

The planned study design assumed that the cumulative incidence of IFI at 100 days post transplant (OLT) in high-risk liver transplant patients would be $12 \%$ on fluconazole and $2 \%$ on $\mathrm{L}$-amB. A sample size of 121 patients per treatment arm was determined to be sufficient to detect this difference at the 2 -sided 0.05 significance level with power of $80 \%$. 


\section{Statistical analysis}

All final data were maintained and analyzed centrally at Rho Federal Systems Division Inc. Authors had access to data and accept responsibility for content and analysis.

The safety population included all patients receiving at least one dose of study drug. Descriptive statistics of demographic characteristics, subject disposition, adverse events (AEs), and deaths were generated using data from this population. The mean, standard deviation, median, and range were computed for continuous safety variables, whereas frequency and percentage distributions are presented for categorical variables. A Kaplan-Meier estimate with 95\% confidence intervals (CI) for the cumulative incidence of death (all-cause) at 100 days after OLT was produced.

Subjects from the safety population who did not meet study entry criteria were excluded from the modified intent-to-treat (MITT) population used for all descriptive analyses of fungal infection outcomes. Kaplan-Meier estimates at 100 days after OLT were generated for the cumulative incidence of (1) subjects with proven or probable IFI and (2) subjects with proven or probable IFI or who received empiric systemic antifungal therapy. For all 100 -day estimates, 95\% CI were computed based on Greenwood's formula for standard error. To provide a range of estimates of the risk of IFI in high-risk patients in the face of ambiguities in infection ascertainment and the effects of empiric antifungal therapy, multiple criteria were used to establish endpoints. Subjects who developed a proven or probable IFI during the follow-up period were considered to have met the primary study endpoint, thereby representing a conservative lower-bound estimate of risk. Less conservative estimates for risk of fungal infection were produced by combining patients with a proven or probable IFI with those receiving empiric systemic antifungal therapies for $>4$ days during any 14-day interval during the study period without evidence of a fungal infection.

For patients who developed IFI, the date of onset was defined as the date the culture was taken.

\section{Results}

\section{Study population}

The study was terminated early because of slow enrollment and unlikely completion of the trial in a timely manner. Between September 1999 and August 2001, 71 subjects were enrolled and randomized at 13 sites. Because of the limited enrollment, all results presented by treatment group are intended to be strictly descriptive rather than inferential and emphasis is placed on the aggregated results. Figure 1 depicts subject flow through the study.

\section{Analysis populations}

Thirty-nine subjects were randomized to the L-amB group, and 32 subjects were randomized to the fluconazole group. Sixty-eight subjects received at least one dose of study drug (safety population). The masked data review committee identified 4 treated subjects who did not meet study entry criteria, and thus 64 subjects (35 L-amB, 29 fluconazole) were included in the MITT population.

\section{Baseline characteristics}

Baseline demographic and clinical characteristics were comparable across treatment groups (Table 1). Sixty percent of subjects were CMV seropositive at baseline. Males outnumbered females in the study (43 vs. 25). The average age was 50 years. The majority of subjects in the study were white/non-Hispanic (78\%).

\section{Summary of study patient disposition}

The disposition of subjects in the safety population is presented in Table 2 . Sixty-two percent $58 \% \mathrm{~L}$-amB, $67 \%$ fluconazole) of subjects completed 14 days of study drug. Early drug discontinuation was due to AEs (in 8 patient), development of IFI as determined by the site investigator (in 4), death (in 3), discharge from hospital (in 5), and other reasons (in 6) including medical decision, subject refusal to continue study medication but agreement to continue follow up, and lack of intravenous access. AEs leading to early discontinuation of study drug in the L-amB group (5 patients) included renal toxicity (in 3), intolerance to study medication with head and neck discomfort (in 1), and tacrolimus toxicity (in 1). AEs leading to early discontinuation of study drug in the fluconazole group (3 patients) included chest pain and shortness of breath (in 1), tacrolimus toxicity/interaction (in 1), and abdominal discomfort with nausea (in 1). The majority of subjects $(79 \%)$ completed study follow-up through 100 days post OLT. Reasons for premature discontinuation from the study included death (in 11), loss to follow-up (in 1), patient withdrawal (in 1), and retransplantation (in 1).

\section{AEs}

Overall, recorded AEs were consistent with the known profile of the study drugs and with the disease state of the subject population. The rate of occurrence of AEs was similar in the 2 treatment groups. Events occurring in more than $20 \%$ of the study population included tremor $(34 \%)$, diarrhea $(28 \%)$, ascites $(26 \%)$, confusion $(24 \%)$, hypotension $(24 \%)$, pleural effusion $(24 \%)$, pyrexia $(24 \%)$, graft rejection $(21 \%)$, nausea $(21 \%)$, and tachycardia $(21 \%)$. 


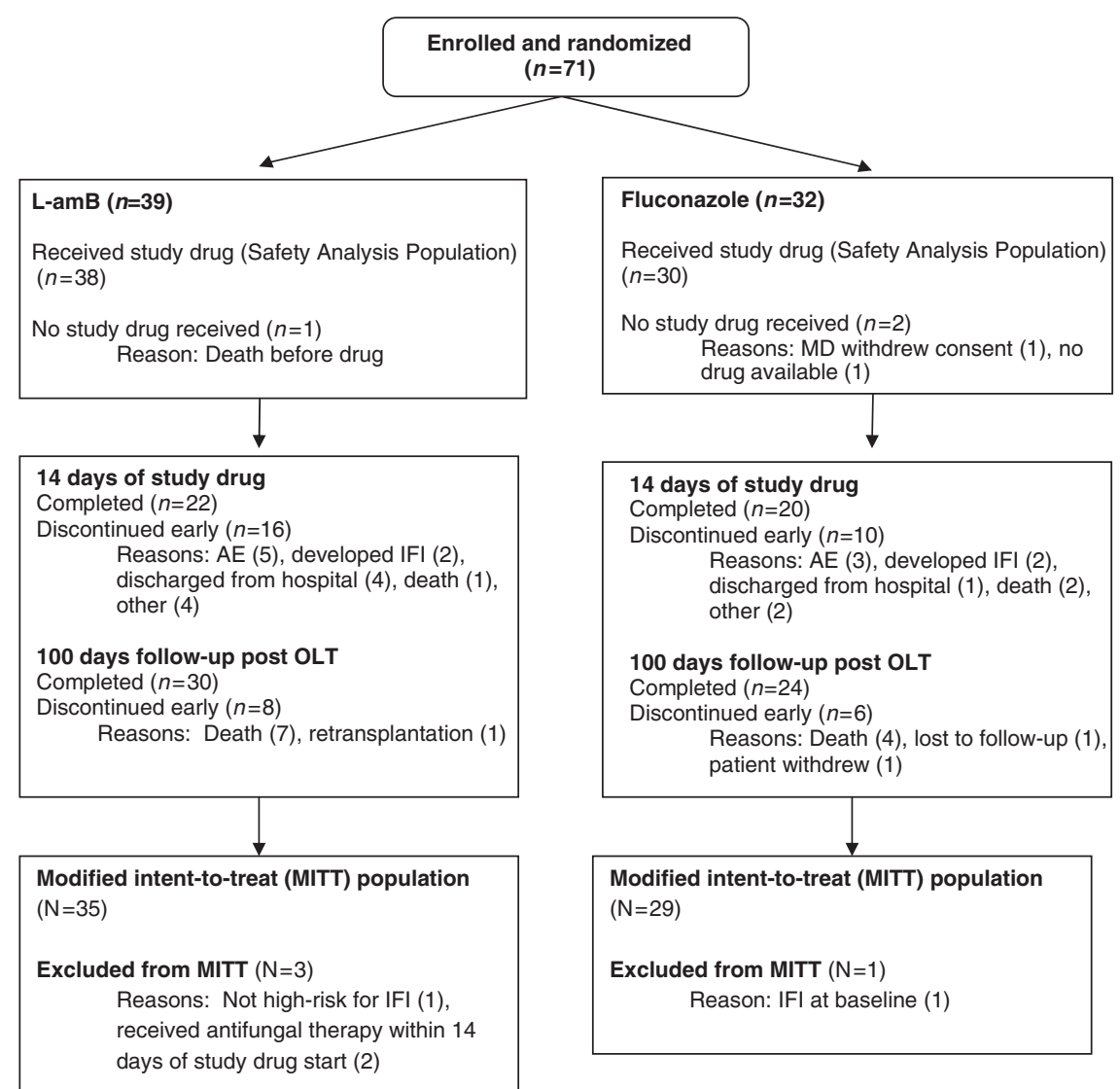

Fig. 1. Participant flow through study. L-amB, liposomal amphotericin B; n, number; AE, adverse events; IFI, invasive fungal infections; OLT, orthotopic liver transplantation.

\section{Mortality}

Among subjects in the safety population, 11 deaths (7 L-amB, 4 fluconazole) occurred within the 100-day study follow-up window resulting in a Kaplan-Meier estimate for mortality at day 100 of 0.17 (95\% CI: $0.10-0.28)$. Estimates for the LamB and fluconazole groups were $0.20(0.10-0.37)$ and 0.13 (0.05- 0.32), respectively. No deaths were attributed to IFI or considered to be related to study drug. The most common cause of death was multi-system organ failure (8 subjects).

\section{Fungal infections}

Ten subjects in the MITT population developed IFI by day 100 (9 proven, 1 probable; $6 \mathrm{~L}$-amB, 4 fluconazole). The number of events was considered too small to make a meaningful comparison. Twelve subjects ( $8 \mathrm{~L}-\mathrm{amB}, 4$ fluconazole) without documented proven or probable IFI received empiric systemic antifungal therapy for additional prophylaxis or empiric therapy for suspected fungal infection or colonization. Kaplan-Meier estimates and 95\% CIs for risk of fungal infection at 100 days after OLT for all subjects in the MITT popu- lation are shown in Table 3. The estimates for the combined population are $17 \%$ for proven and probable IFI and $37 \%$ considering proven or probable IFI or receipt of empiric sys-

Baseline demographic and clinical characteristics: safety population

\begin{tabular}{|c|c|c|c|}
\hline Characteristic & $\begin{array}{l}\text { All } \\
(N=68)\end{array}$ & $\begin{array}{l}\text { L-amB } \\
(N=38)\end{array}$ & $\begin{array}{l}\text { Fluconazole } \\
(N=30)\end{array}$ \\
\hline CMV positive, $n$ (\%) & $41(60 \%)$ & $23(61 \%)$ & $18(60 \%)$ \\
\hline Age, mean (SD) & $49.9(9.3)$ & $48.4(8.6)$ & $51.9(9.8)$ \\
\hline Male, $n(\%)$ & $43(63 \%)$ & $24(63 \%)$ & $19(63 \%)$ \\
\hline \multicolumn{4}{|l|}{ Race/ethnicity, $n$ (\%) } \\
\hline White, non-Hispanic & $53(78 \%)$ & $33(87 \%)$ & $20(67 \%)$ \\
\hline African-American, non-Hispanic & $6(9 \%)$ & $2(5 \%)$ & $4(13 \%)$ \\
\hline Hispanic & $4(6 \%)$ & $1(3 \%)$ & $3(10 \%)$ \\
\hline Asian & $1(1 \%)$ & $1(3 \%)$ & $0(0 \%)$ \\
\hline Other & $4(6 \%)$ & $1(3 \%)$ & $3(10 \%)$ \\
\hline
\end{tabular}

Table 1 
Subject disposition: safety population

\begin{tabular}{|c|c|c|c|}
\hline Characteristic & $\begin{array}{l}\text { All } \\
(N=68) \\
n(\%)\end{array}$ & $\begin{array}{l}\text { L-amB } \\
(N=38) \\
n(\%)\end{array}$ & $\begin{array}{l}\text { Fluconazole } \\
(N=30) \\
n(\%)\end{array}$ \\
\hline $\begin{array}{l}\text { Failed to complete } 14 \text { days of } \\
\text { study drug }\end{array}$ & $26(38 \%)$ & $16(42 \%)$ & $10(33 \%)$ \\
\hline \multicolumn{4}{|c|}{$\begin{array}{l}\text { Primary reason for early discontinuation } \\
\text { of study drug }\end{array}$} \\
\hline Adverse event & $8(12 \%)$ & $5(13 \%)$ & $3(10 \%)$ \\
\hline Patient developed IFI & $4(6 \%)$ & $2(5 \%)$ & $2(7 \%)$ \\
\hline Discharged from hospital & $5(7 \%)$ & $4(11 \%)$ & $1(3 \%)$ \\
\hline Death & $3(4 \%)$ & $1(3 \%)$ & $2(6 \%)$ \\
\hline Other & $6(9 \%)$ & $4(11 \%)$ & $1(3 \%)$ \\
\hline $\begin{array}{l}\text { Completed } 100 \text { days post-OLT } \\
\text { follow-up }\end{array}$ & $54(79 \%)$ & $30(79 \%)$ & $24(80 \%)$ \\
\hline \multicolumn{4}{|c|}{ Prematurely discontinued from study } \\
\hline Death & $11(16 \%)$ & $7(18 \%)$ & $4(13 \%)$ \\
\hline Lost to follow-up & $1(1 \%)$ & 0 & $1(3 \%)$ \\
\hline Patient withdrew & $1(1 \%)$ & 0 & $1(3 \%)$ \\
\hline Retransplantation & $1(1 \%)$ & $1(3 \%)$ & 0 \\
\hline
\end{tabular}

\section{Table 2}

tem antifungal therapy. Nine Candida species (C. albicans in 2, C. glabrata in 4, C.parapsilosis in 2, and C. tropicalis in 1) and 1 C. neoformans infections occurred. The 3 Candida infections, occurring in those who received fluconazole prophylaxis, were caused by $C$. glabrata. Most infections occurred early, within 21 days of OLT, and were predominantly intraabdominal in origin, based on cultures obtained at the time of reoperation or percutaneous aspiration (6 of 10) (Table 4).

\section{High-risk criteria}

Tables 5 and 6 summarize high-risk criteria at enrollment for the MITTanalysis population by treatment group and by development of IFI, respectively. Receipt of $\geq 40 \mathrm{U}$ of cellular blood products, baseline fungal colonization, and elevated serum creatinine were the most common risk factors for eligibility, with similar frequencies in each treatment group. More subjects in the L-amB group returned to the operating room within 5 days of OLT $(20 \%)$ than in the fluconazole group $(7 \%)$. The reverse was true for those undergoing retransplantation ( $6 \% \mathrm{~L}-\mathrm{amB}, 17 \%$ fluconazole). Most of the subjects enrolled had 2 high-risk criteria (42, $66 \%) ; 14(22 \%), 7(11 \%)$, and $1(2 \%)$ met 3,4 , and 5 high-risk criteria, respectively. Subjects with IFI appeared to be more likely to have choledochojejunostomy type of anastomosis $(60 \%$ vs. $31 \%)$ and retransplantation ( $30 \%$ vs. $7 \%)$ than subjects without IFI. The rate of IFI among LTRs with 2 risk factors $(4 / 42 ; 10 \%)$ was lower than among those with 3 or more risk factors $(6 / 22 ; 27 \%$ ), suggesting a possible additive effect of risk factors.

\section{Discussion}

A recently updated meta-analysis of the effects of prophylaxis in solid organ transplant recipients demonstrated a significant reduction in IFI in LTRs treated with fluconazole prophylaxis, but no reduction in mortality (22). The authors concluded that antifungal prophylaxis is warranted in high-risk individuals or those in transplant centers with high rates of IFI. Our study is the first to describe the development of IFI in high-risk LTRs receiving antifungal prophylaxis and supports this strategy. This randomized antifungal prophylaxis trial in high-risk LTR was prematurely terminated because of slow enrollment and poor likelihood of meeting enrollment goals within a reasonable time period. Nevertheless, this study resulted in 4 important observations that are related to 1) the tolerance and duration of antifungal prophylaxis treatment; 2) the predominant types of high-risk criteria in subjects who developed IFI and the additive effect of high risk factors; 3 ) the rate, timing, and types of IFI; and 4) survival of highrisk LTR 100 days post transplant.

Kaplan-Meier (KM) day 100 estimates and 95\% confidence intervals (CI) for risk of fungal infection: modified intent-to-treat population

\begin{tabular}{|c|c|c|c|}
\hline \multirow[b]{2}{*}{ Fungal infection endpoint } & \multicolumn{3}{|c|}{ Day 100 KM estimate ( $95 \% \mathrm{Cl})$} \\
\hline & Combined treatments & L-amB & Fluconazole \\
\hline Proven or probable IFI & $0.17(0.09-0.29)$ & $0.18(0.09-0.36)$ & $0.15(0.06-0.35)$ \\
\hline Proven or probable IFI or empiric systemic antifungal therapy & $0.37(0.26,0.50)$ & $0.43(0.28,0.62)$ & $0.29(0.16,0.50)$ \\
\hline
\end{tabular}

Table 3 
Proven and probable invasive fungal infections (IFI): modified intent-to-treat population

\begin{tabular}{|c|c|c|c|c|c|}
\hline $\begin{array}{l}\text { Days from } \\
\text { OLT to IFI }\end{array}$ & $\begin{array}{l}\text { Type of } \\
\text { infection }\end{array}$ & $\begin{array}{l}\text { Treatment } \\
\text { group }\end{array}$ & $\begin{array}{l}\text { Causative } \\
\text { organism }\end{array}$ & Infection site & High-risk criteria \\
\hline 3 & Proven IFI & Fluconazole & C. glabrata & $\begin{array}{l}\text { Intra-abdominal/ } \\
\text { peritoneal fluid }\end{array}$ & $\begin{array}{l}\text { Retransplantation, cellular blood products } \geq 40 \mathrm{U} \text {, } \\
\text { serum } \mathrm{Cr} \geq 2.0 \text {, dialysis within } 48 \mathrm{~h} \text {, Candida } \\
\text { species isolated }\end{array}$ \\
\hline 6 & Proven IFI & $\begin{array}{l}\text { Liposomal } \\
\text { amphotericin B }\end{array}$ & C. parapsilosis & Blood & $\begin{array}{l}\text { Cellular blood products } \geq 40 \mathrm{U} \text {, Candida species } \\
\text { isolated }\end{array}$ \\
\hline 7 & Probable IFI & $\begin{array}{l}\text { Liposomal } \\
\text { amphotericin B }\end{array}$ & C. parapsilosis & Right IJ catheter tip & Choledojejunostomy, cellular blood products $\geq 40 \mathrm{U}$ \\
\hline 11 & Proven IFI & $\begin{array}{l}\text { Liposomal } \\
\text { amphotericin B }\end{array}$ & C. albicans & $\begin{array}{l}\text { Intra-abdominal/ } \\
\text { peritoneal fluid }\end{array}$ & $\begin{array}{l}\text { Choledojejunostomy, cellular blood products } \geq 40 \mathrm{U} \text {, } \\
\text { Candida species isolated, returned to OR }\end{array}$ \\
\hline 12 & Proven IFI & Fluconazole & $\begin{array}{l}\text { Cryptococcus } \\
\text { neoformans }\end{array}$ & Sputum & $\begin{array}{l}\text { Serum } \mathrm{Cr} \geq 2.0 \text {, dialysis within } 48 \mathrm{~h}, \text { Candida } \\
\text { species isolated }\end{array}$ \\
\hline 14 & Proven IFI & $\begin{array}{l}\text { Liposomal } \\
\text { amphotericin B }\end{array}$ & C. albicans & $\begin{array}{l}\text { Intra-abdominal/ } \\
\text { peritoneal fluid }\end{array}$ & $\begin{array}{l}\text { Choledojejunostomy, retransplantation, cellular blood } \\
\text { products } \geq 40 \mathrm{U} \text {, serum } \mathrm{Cr} \geq 2.0 \text {, dialysis within } \\
48 \mathrm{~h} \text {, Candida species isolated }\end{array}$ \\
\hline 22 & Proven IFI & $\begin{array}{l}\text { Liposomal } \\
\text { amphotericin B }\end{array}$ & C. tropicalis & $\begin{array}{l}\text { Intra-abdominal/ } \\
\text { peritoneal fluid }\end{array}$ & $\begin{array}{l}\text { Choledojejunostomy, cellular blood products } \geq 40 \mathrm{U} \text {, } \\
\text { Candida species isolated }\end{array}$ \\
\hline 36 & Proven IFI & Fluconazole & C. glabrata & $\begin{array}{l}\text { Intra-abdominal/ } \\
\text { bile leak }\end{array}$ & $\begin{array}{l}\text { Cellular blood products } \geq 40 \mathrm{U} \text {, serum } \mathrm{Cr} \geq 2.0 \text {, } \\
\text { dialysis within } 48 \mathrm{~h} \text {, Candida species isolated }\end{array}$ \\
\hline 46 & Proven IFI & Fluconazole & C. glabrata & Blood & $\begin{array}{l}\text { Choledojejunostomy, retransplantation, cellular blood } \\
\text { products } \geq 40 \mathrm{U} \text {, Candida species isolated }\end{array}$ \\
\hline 93 & Proven IFI & $\begin{array}{l}\text { Liposomal } \\
\text { amphotericin B }\end{array}$ & C. glabrata & $\begin{array}{l}\text { Intra-abdominal/ } \\
\text { liver fluid }\end{array}$ & Choledojejunostomy, cellular blood products $\geq 40 \mathrm{U}$ \\
\hline
\end{tabular}

Table 4

Approximately one-third of study subjects did not complete 14 days of assigned study therapy. The 2 most common reasons for early discontinuation were development of AEs in $12 \%$ and early discharge from the hospital in $7 \%$. These reasons reflect the underlying conditions of these very ill high-risk LTRs, the toxicities of antifungal therapies, and indicate a need for oral alternatives for high-risk LTRs who do well after surgery and are quickly discharged from the hospital. In our study, the vast majority of AEs were unrelated to study drug; those that were treatment-related were within the expected range for the drugs studied.

Retransplantation and a choledochojejunostomy type of anastomosis were more common perioperative risk factors in subjects who developed IFI. A choledochojejunostomy anastomosis, in which the donor common bile duct is diverted to the recipient's jejunal loop, potentiates the risk of colonization of the biliary system with upper gastrointestinal tract pathogens, such as Candida species. Others have found that retransplantation and choledochojejunostomy types of anastomosis are significant risks for fungal infection after $\operatorname{OLT}(3,7,8,13,16,23)$. Our data suggest that there may be an additive effect of high-risk factors in the genesis of IFI.

In this clearly defined high-risk group of LTRs who received systemic antifungal prophylaxis in the initial 2 weeks after OLT in addition to topical oral nystatin, the adjusted IFI attack rate by day 100 was approximately $17 \%$. Other studies of antifungal prophylaxis in LTRs have largely not distinguished high- from low-risk subjects. Attack rates for IFI in treated groups in these studies have ranged from $0 \%$ to $15 \%(13,14,24-27)$. In our study, the rate of IFI was approximately half that of previously reported untreated high-risk LTRs, which suggests a benefit of prophylaxis $(8,16,19)$. In addition, the overall rate of IFI in our study population provides insight into the frequency of IFI for calculating sample size in future studies of prophylaxis.

Invasive candidiasis, predominantly intra-abdominal, was the most common IFI occurring in this study. A choledochojejunostomy type of anastomosis was employed more frequently in the infected group and may play a role in the predominance of intra-abdominal infections overall. Non-albicans Candida species caused the majority of IFI. 
High-risk criteria at enrollment by treatment group: modified intent-to-treat population

\begin{tabular}{|c|c|c|c|}
\hline Characteristic & All $(N=64) n(\%)$ & L-amB $(N=35) n(\%)$ & Fluconazole $(N=29) n(\%)$ \\
\hline \multicolumn{4}{|l|}{ Number of high-risk criteria at enrollment } \\
\hline 2 & $42(66 \%)$ & $24(69 \%)$ & $18(62 \%)$ \\
\hline 3 & $14(22 \%)$ & $9(26 \%)$ & $5(17 \%)$ \\
\hline 4 & $7(11 \%)$ & $1(3 \%)$ & $6(21 \%)$ \\
\hline 5 & $1(2 \%)$ & $1(3 \%)$ & 0 \\
\hline \multicolumn{4}{|l|}{ High-risk criteria } \\
\hline Choledochojejunostomy anastomosis & $2335 \%$ & $14(40 \%)$ & $9(31 \%)$ \\
\hline Retransplantation & $7(11 \%)$ & $2(6 \%)$ & $6(17 \%)$ \\
\hline Intraoperative use of $>40$ units blood products & $46(72 \%)$ & $25(71 \%)$ & $21(72 \%)$ \\
\hline Pre-op $\mathrm{Cr}>2.0 \mathrm{mg} / \mathrm{dL}$ or any dialysis $48 \mathrm{~h}$ pre-op & $29(45 \%)$ & $13(37 \%)$ & $16(55 \%)$ \\
\hline Candida species isolated from surveillance culture & $45(70 \%)$ & $23(66 \%)$ & $22(76 \%)$ \\
\hline Return to the OR within 5 days post OLT & $9(14 \%)$ & $7(20 \%)$ & $2(7 \%)$ \\
\hline
\end{tabular}

$\mathrm{N}$, number; L-amB, liposomal amphotericin B; Cr, creatinine; OR, operating room; OLT, orthotopic liver transplantation.

\section{Table 5}

In the fluconazole group, all IFI were caused by C.glabrata, which has higher rates of fluconazole resistance. As in other studies, the majority of Candida infections occurred within the first month after transplantation $(7,8,14,16,20$, $26,28)$. The timing of infection suggests that a prophylaxis period of one month might be preferable.

In our study, in which a little more than half of the patients received prophylaxis with a drug effective against all yeasts and molds, no infections due to Aspergillus or other filamentous fungi occurred in the first 100 days after OLT. This negligible attack rate for Aspergillus may simply reflect the follow-up period studied rather than drug efficacy. Singh et al. (17) documented a trend toward invasive aspergillosis occurring more than 3 months after OLT in the majority of patients $(55 \%)$ studied after 1998. In contrast, 3 of the 7 IFI occurring in the cohort of low-risk

High-risk criteria at enrollment by development of invasive fungal infections (IFI): modified intent-to-treat population

\begin{tabular}{|c|c|c|c|}
\hline Characteristic & All $(N=64) n(\%)$ & No IFI $(N=54) n(\%)$ & IFI $(N=10) n(\%)$ \\
\hline \multicolumn{4}{|l|}{ Number of high-risk criteria at enrollment } \\
\hline 2 & $42(66 \%)$ & $38(70 \%)$ & $4(40 \%)$ \\
\hline 3 & $14(22 \%)$ & $12(22 \%)$ & $2(20 \%)$ \\
\hline 4 & $7(11 \%)$ & $4(7 \%)$ & $3(30 \%)$ \\
\hline 5 & $1(2 \%)$ & & $1(10 \%)$ \\
\hline \multicolumn{4}{|l|}{ High-risk criteria } \\
\hline Choledochojejunostomy anastomosis & $23(35 \%)$ & $17(31 \%)$ & $6(60 \%)$ \\
\hline Retransplantation & 7 (11\%) & $4(7 \%)$ & $3(30 \%)$ \\
\hline Intraoperative use of $>40$ units blood products & $46(72 \%)$ & $37(69 \%)$ & $9(90 \%)$ \\
\hline Pre-op $\mathrm{Cr}>2.0 \mathrm{mg} / \mathrm{dL}$ or any dialysis $48 \mathrm{~h}$ pre-op & $29(45 \%)$ & $25(46 \%)$ & $4(40 \%)$ \\
\hline Candida species isolated from surveillance culture & $45(70 \%)$ & $37(69 \%)$ & $8(80 \%)$ \\
\hline Return to the OR within 5 days post OLT & $9(14 \%)$ & $8(15 \%)$ & $1(10 \%)$ \\
\hline
\end{tabular}

Table 6 
patients followed prospectively were due to invasive aspergillosis, and 2 occurred within 11 days of OLT (20). In highand low-risk cohorts taken together, the preponderance of early, predominantly non-albicans Candida species and Aspergillus species infections suggest that a future prophylaxis trial in high-risk LTRs should use broad-spectrum antifungal agents, available in oral form, that are active against all Candida species as well as Aspergillus species and given for at least 30 days postoperatively.

In this high-risk LTR population, the 100-day survival rate of $79 \%$ compares favorably to most previous studies examining mortality in LTRs of varying degrees of risk $(6,7,16,29)$. Moreover, $95 \%$ of low-risk patients from the same transplant centers survived 100 days without IFI-related deaths (20). Whether or not antifungal prophylaxis contributed to improved survival in the high-risk cohort cannot be surmised from these data.

In summary, we conducted a randomized controlled antifungal prophylaxis trial for high-risk LTRs assessed perioperatively and followed for 100 days. Despite early termination of the trial and lack of ability to compare treatments in a statistically meaningful manner, our data suggest that a lipid formulation amphotericin $\mathrm{B}$ and fluconazole are well tolerated in high-risk LTRs, and when IFI occur, they are caused predominantly by Candida species infecting the intra-abdominal space within one month of transplantation. Retransplantation and a choledochojejunostomy type of anastomosis may be particularly strong risk factors for IFI. Future antifungal prophylaxis trials of broadly active oral agents should target selected high-risk LTRs for at least the first month after transplantation.

\section{Acknowledgements:}

The study was conducted through the Mycology Study Group (MSG) and Bacteriology and Mycology Study Group (BAMSG) clinical research network with assistance from the data coordinating center, the Bacteriology and Mycology Statistical and Operations Unit (BAMBU). We wish to thank the study coordinators and all other staff at the participating sites for their assistance in conducting the study. Special thanks to Louise Zimmer, Project Director, for her valuable assistance with this study and manuscript development.

Grant support: This project has been funded in part with Federal Funds from the National Institute of Allergy and Infectious Diseases, National Institutes of Health under contract nos. N01-AI-65296 and N01-AI-15441, and by Fujisawa Healthcare Inc.

NIAID Trial NCT00001107 at clinicaltrials.gov

The content of this publication does not necessarily reflect the views or policies of the Department of Health and
Human Services, nor does mention of trade names, commercial products, or organizations imply endorsement by the United States Government.

Potential conflicts of interest: Susan Hadley: Dr Hadley has served on the advisory boards of ScheringPlough and Pfizer. She also serves on the speaker's bureau for Schering-Plough. Charmaine Huckabee: no conflict. Peter G. Pappas: Dr Pappas receives research grant support from Merck, Pfizer, Astellas, Schering-Plough, and Basilea. He serves as an ad hoc advisor for Merck, Pfizer, and Basilea; he receives speaking honoraria from Merck, Pfizer, and Astellas. Jennifer Daly: Dr Daly is participating in antifungal research for Basilea (Switzerland). John Rabkin: no conflict. Robert M. Merion: no conflict. Carol A. Kauffman: Dr Kauffman has research grants from Merck, Astellas, and Schering-Plough. She also serves on the speakers' bureaus for Astellas, Pfizer, and Merck.

\section{References}

1. Wajszczuk CP, Dummer JS, Ho M, et al. Fungal infections in liver transplant recipients. Transplantation 1985; 40: 347-353.

2. Kusne S, Dummer JS, Singh N, et al. Infections after liver transplantation: an analysis of 101 consecutive cases. Medicine 1988; 67: 132-143.

3. Castaldo P, Stratta RJ, Wood RP, et al. Clinical spectrum of fungal infections after orthotopic liver transplantation. Arch Surg 1991; 126: 149-156.

4. Paya CV. Fungal infection in solid-organ transplantation. Clin Infect Dis 1993; 16: 677-688.

5. Fung JJ. Fungal infection in liver transplantation. Transpl Infect Dis 2002; 4: 18-23.

6. Gayowski T, Marino IR, Singh N, et al. Orthotopic liver transplantation in high-risk patients: risk factors associated with mortality and infectious morbidity. Transplantation 1998; 65 : 499-504.

7. Rabkin JM, Oroloff SL, Corless CL, et al. Association of fungal infection and increased mortality in liver transplant recipients. Am J Surg 2000; 179: 426-430.

8. Collins LA, Samore MH, Roberts MS, et al. Risk factors for early invasive fungal infections complicating orthotopic liver transplantation. J Infect Dis 1994; 170: 644-652.

9. Viviani MA,Tortorano AM, Malaspina C, et al. Surveillance and treatment of liver transplant recipients for candidiasis and aspergillosis. Eur J Epidemiol 1992; 8: 433-436.

10. Wade JJ, Rolando N, Hayllar K, Philpott-Howard J, Casewell MW, Williams R. Bacterial and fungal infections after liver transplantation: an analysis of 284 patients. Hepatology 1995; 21: 1328-1336.

11. Patel R, Portela D, Bradley AD, et al. Risk factors of invasive Candida and non-Candida fungal infections after liver transplantation. Transplantation 1996; 62: 926-934.

12. Tollemar J, Hockerstedt K, Ericzon BG, Jalanko H, Ringden O. Prophylaxis with liposomal amphotericin B (AmBisome) prevents fungal infections in liver transplant recipients: long-term results of a randomized, placebo-controlled trial. Transplant Proc 1995; 27: 1195-1198. 
13. Winston DJ, Pakrasi A, Busuttil RW. Prophylactic fluconazole in liver transplant recipients. A randomized, double-blind, placebocontrolled trial. Ann Intern Med 1999; 131: 729-737.

14. Winston DJ, Busuttil RW. Randomized controlled trial of oral itraconazole solution versus intravenous/oral fluconazole for prevention of fungal infections in liver transplant recipients. Transplantation 2002; 74: 688-695.

15. Singh N, Arnow PM, Bonham A, et al. Invasive aspergillosis in liver transplant recipients in the 1990's. Transplantation 1997; 64: 716-720.

16. Hadley S, Samore MH, Lewis WD, Jenkins RL, Karchmer AW, Hammer SM. Major infectious complications after orthotopic liver transplantation and comparison of outcomes in patients receiving cyclosporine or FK506 as primary immunosuppression. Transplantation 1995; 59: 851-859.

17. Singh N, Avery RK, Munoz P, et al. Trends in risk profiles for and mortality associated with invasive aspergillosis among liver transplant recipients. Clin Infect Dis 2003; 36: 46-52.

18. Husain S, Tollemar J, Dominguez EA, et al. Changes in the spectrum and risk factors for invasive candidiasis in liver transplant recipients: prospective, multicenter, case-controlled study. Transplantation 2003; 75: 2023-2029

19. Karchmer AW, Samore MH, Hadley S, Collins LA, Jenkins RL, Lewis WD. Fungal infections complicating orthotopic liver transplantation. Trans Am Clin Climatol Assoc 1995; 106: 38-48.

20. Pappas PG, Andes D, Schuster M, et al. Invasive fungal infections in low-risk liver transplant recipients: a multi-center prospective observational study. Am J Transplant 2006; 6: 386-391.

21. Ascioglu S, Rex JH, De Pauw B, et al. Defining opportunistic invasive fungal infections in immunocompromised patients with cancer and hematopoietic stem cell transplants: an international consensus. Clin Infect Dis 2002; 34: 7-14.

22. Playford EG, Webster AC, Sorell TC, Craig JC. Antifungal agents for preventing fungal infections in solid organ transpl recipients. Cochrane Database Syst Rev 2004; CD004291.

23. Fortun J, Martin-Davila P, Moreno S, et al. Risk factors for invasive aspergillosis in liver transplant recipients. Liver Transpl 2002; 8: 1065-1070.

24. Tollemar J, Ringden O, Andersson S, Sundberg P, Ljungman P, Tyden G. Randomized double-blind study of liposomal amphotericin B (AmBisome) prophylaxis of invasive fungal infections in bone marrow transplant recipients. Bone Marrow Transplant 1993; 12: 577-582.

25. Zwaveling JH, Maring JK, Klompmaker IJ, et al. Selective decontamination of the digestive tract to prevent postoperative infection: a randomized placebo-controlled trial in liver transplant patients. Crit Care Med 2002; 30: 1204-1209.

26. Lumbreras C, Cuervas-Mons V, Jara P, et al. Randomized trial of fluconazole versus nystatin for the prophylaxis of Candida infection following liver transplantation. J Infect Dis 1996; 174: 583-588.

27. Singhal S, Ellis RW, Jones SG, et al. Targeted prophylaxis with amphotericn B lipid complex in liver transplantation. Liver Transpl 2000; 6: 588-595.

28. Tollemar J, Hockerstedt K, Ericzon BG, Jalanko H, Ringden O. Liposomal amphotericin B prevents invasive fungal infections in liver transplant recipients. Transplantation 1995; 59: 45-50.

29. Nieto-Rodriguez JA, Kusne S, Manez R, et al. Factors associated with the development of candidemia and candidemia-related death among liver transplant recipients. Ann Surg 1996; 233: $70-76$. 